for NATURE, are photographs of a most convincing character, in which the Hesperopithecus molar (Fig. 2, $\mathrm{r}-4$ ), in three aspects, is placed directly between corresponding molars of a chimpanzee (right and left) which most nearly resemble it. It will be seen at once (x) that the Hesperopithecus molar, although greatly water-worn, has entirely different proportions from the chimpanzee molar: it is much broader transversely; it is much narrower in the fore-and-aft dimensions. This affords positive evidence that Hesperopithecus had a shorter facial region than the chimpanzee. In this respect it approaches the mongoloid human type (Fig. 2, 5) more closely than it does any of the anthropoid ape types ; (2) the roots of the Hesperopithecus molar are much more robust and more human in proportion than those of any of the frugivorous apes ; (3) the upper molar of Hesperopithecus, while resembling the upper molars of certain American Indians of mongoloid type in several absolute measurements, differs widely in the more asymmetrical form of the crown, which is broader in front and narrower behind, whereas in the mongoloid human molars the crown is more symmetrical; (4) the type upper molar of Hesperopithecus differs from the corresponding molar in the Trinil Ape-man (Pithecanthropus) (Fig. 2,3 ) in nearly all its absolute measurements ; but it resembles the Pithecanthropus molar in the great size of the internal (lingual) fang, also in the wide separation of the internal (lingual) and external (anterobuccal) fangs. It also resembles Pithecanthropus in the evenly concive depression of the grinding surface, which is quite unlike the ridged form of the grinding surface observed in a chimpanzee molar (Fig. 2, 2-6) ; (5) as for the comparison suggested by Dr. Smith Woodward with the third lower molar of the Pliocene bear (Hyænarctos), the differences are so fundamental that it is difficult to find any single point of agreement; the molar of Hesperopithecus very clearly conforms to the flattened tritubercular to quadritubercular type which characterises all the upper molars of anthropoid apes and of man.

Thus, after making due allowance for the characters resulting from the prolonged natural usage of the Hesperopithecus molar, also for characters due to long exposure to erosion and stream action, and to percussion by the sharp sand of the river bed, there nevertheless remain five outstanding sharacters, as well as many highly significant details of character, which tend to show that this tooth belongs to one of the higher Primates, and that this genus ultimately may be included either within the Simiidæ (anthropoid apes), or near certain ancestors of the Hominidæ (human stock).

I desire to summarise with emphasis my original statements about this tooth, namely, that among existing anthropoid apes it is nearest to $\mathrm{m}^{2}$ of the chimpanzee, but the resemblance is still very remote . . . that the proportions of the molar crown of Hesperopithecus are about the same as in Homo sapiens mongoloideus (American Indian) type . . . that there is also a distant human resemblance in the molar pattern of Hesperopithecus to the low, basin-shaped, channelled crown in certain examples of Homo sapiens ... that the Hesperopithecus molar cannot be said to resemble any known type of human molar very closely. It is certainly not closely related to Pithecanthropus erectus in the structure of the molar crown . . . it is therefore a new and independent type of Primate, and we must seek more material before we can determine its relationships.

My original characterisation and description have been fully confirmed by the intensive research of the past two months. I have not stated that Hesperopithecus was either an Ape-man or in the direct line of human ancestry, because I consider it quite possible that we may discover anthropoid apes (Simiidæ) with teeth closely imitating those of man (Hominidæ), just as we have discovered in the true Piltdown man (Eoanthropus) teeth closely imitating those of the chimpanzee. There are so many crisscross adaptations of this kind among the mammals that we can never be sure about the family relationships of an animal until we secure not only the teeth but considerable parts of the skeleton as well. No anatomist in the possession of Pithecanthropus molars only would have discovered the human resemblance which is indubitably established by the roof of the cranium, by the shape of the brain, and by the shape of the thigh bone. For similar skeletal parts of Hesperopithecus we are making most determined and prolonged search in the type locality ; it is not at all probable that the desired evidence will be easy to secure. Until we secure more of the dentition, or parts of the skull or of the skeleton, we cannot be certain whether Hesperopithecus is a member of the Simiidæ or of the Hominidæ.

\title{
Science in Egypt.
}

By Col. H. G. Lyons, F.R.S.

THE important part which modern science can play in the economical development of natural resources is generally recognised to-day, but nowhere may this be seen more clearly than in Egypt, with its subtropical climate, its controlled water-supply, and its immunity from the vagaries of the weather which affect more northern latitudes. Here a population which in 1882 was under seven millions has now grown to more than twelve millions, and inhabits a cultivable area which does not exceed seven million acres all intensively cultivated; for much of the area, which was formerly flooded annually and then furnished a single crop after the river had fallen, is now under perennial cultivation with a supply of water at all seasons, and consequently up to five crops in two years are taken from it. Under these conditions the most economical use of the material resources that science can devise, and all the improvements that it can suggest, are of the utmost importance to the country.

During Egypt's period of financial difficulty the provision for scientific work was very meagre, but with the reorganisation of the irrigation and the introduction of reforms, an improving revenue enabled gradually increasing grants to be made to state departments, and many of them have, during the past thirty years, established services in which scientific work of value and importance has been carried on.

Some scientific work had been initiated at a much 
earlier date, for the medical school at Qasr el Aini was established early in the last century, and about I860 a 2o-centimetre astronomical refracting telescope by Brünner of Paris, with an equatorial mounting, was set up at Abbassia; a four-metre base-bar together with two 40-centimetre theodolites and a portable transit instrument by the same firm were purchased for the survey of Egypt which was then projected, but which did not become an accomplished fact until about fifty years later.

To-day there are at least a dozen services occupied primarily with work of a scientific character.

The Survey of Egypt is the successor of the earlier surveys of 1823,1853 and 1878 , but none of these were ever completed nor had they any scientifically organised control. It now comprises the cadastral survey, the topographical survey, the desert survey, and the geological survey.

The cadastral survey is of special importance in Egypt on account of the high value of agricultural land, and the exceptional degree of subdivision of the holdings. The network of triangulation on which it is based now covers the Nile Valley and Delta, and is controlled by the first-order triangulation now in progress, which is of the standard demanded in international geodetic work. The topographical survey utilises the material provided by the cadastral survey and adds to it all topographical information besides extending the maps beyond the limits of the cultivated land, to meet the needs of different branches of the public service. There are now published series of map sheets on scales of $I: 2500$, I : ro,000, and I : 50,000, covering all the inhabited area of the country, while other maps on scales of $I: 250,000$ and $I: I, 000,000$ include the large areas of desert as well.

Survey work as it is extended into the desert assumes a special character, for on account of the large areas to be covered, the difficulties of transport, and the absence of all artificial topographical features, special methods of surveying have been adopted. This work is now in the hands of the Desert Survey, which also undertake the precise location and demarcation of prospecting and mining areas leased by the Government.

On the highly cultivated alluvial plains of the Nile Valley and the Delta accurate levelling is of special importance, so a network of levelling of high precision has been carried over them and extended into the Sudan along the Nile. Besides this the cultivated area throughout Egypt has been contoured at 50 centimetre intervals. At the headquarters of the Survey of Egypt are drawing, photographic, and printing offices in which are produced the maps of the various surveys and also those which are required by the geological survey and by other State departments.

In 1896 a geological reconnaissance of Egyptian territory was authorised which, at the end of five years, developed into a geological survey. The staff has always been small, but a very large amount of valuable work has been done under the difficulties and limitations imposed by desert travel.

Not only have the mineral resources of the country been located and described, thereby becoming available for commercial purposes, such as the phosphate deposits in Egypt and manganese deposits in Sinai, but our knowledge of the structure and stratigraphy of north-eastern Africa has also been greatly advanced, and the interesting fauna of Lower Eocene age which was brought to light in the desert to the west of the Fayum has greatly extended our knowledge of the past history of the African continent. Geological work has been carried out for several years in connexion with petroleum research in the Red Sea area, and the results have been published in various reports. The records of the geological survey and the collections which fill its museum provide a store of information relating to the structure and stratigraphy of the Nile Basin and north-eastern Africa.

The Physical Department, which until a few years ago was part of the Survey Department, and is now a part of the Ministry of Public Works, includes the Helwan Observatory with its time service, the meteorological service, the service of weights and measures, and the hydrological investigations in connexion with the Nile. The observatory, which was formerly at Abbassia, was removed in 1904 to Helwan, $20 \mathrm{~km}$. south of Cairo, because the building at Abbassia was wholly unsuitable and the extension of the electric tramways to its neighbourhood prevented all magnetic work. In it the 30 -inch reflecting telescope at Helwan is employed in the photography of southern nebulæ, of comets when they appear, and of Jupiter's eighth satellite, which has been observed almost exclusively by Greenwich and Helwan since its discovery.

The time service is also directed from the observatory, and the observatory clock transmits the noon time signals which are utilised at Cairo, Alexandria, Port Said, and at Khartoum. Magnetic observations are carried out both by means of magnetographs and by weekly absolute determinations. The meteorological service of Egypt and the Sudan includes, besides the central observatory at Helwan, 57 climatological stations, of which 23 are in Egypt, 27 in the Sudan, and 7 in Palestine, and about 230 rainfall stations in Egypt, the Sudan, and Abyssinia. First established to study the conditions determining the Abyssinian rainfall, and consequently the Nile Flood, it has now a much wider importance and is one of the recognised national meteorological services.

The increasing demands of agriculture and its dependence on the supply of water provided by the Nile have necessitated a high precision in river-gauging, and the hydrological work which this involves is now centred in the Physical Department, where the records of 70 river-gauge stations are discussed, and hydrological investigations are undertaken. The storage of water in the valley of the Nile at various points, the need for accurate measurements of the discharge throughout the low stage of the river, the study of the effect of turbulence in the water at flood stage, etc. present a series of physical problems which are of direct importance to Egypt, as well as being of great interest to many other countries.

The department is also charged with the inspection of weights and measures throughout the country, and the prototype standard metre and the secondary standards of length, which were acquired for the purpose of the Survey of Egypt, are now kept at the Helwan Observatory, where any comparisons desired are earried out in a well-equipped comparator house.

NO. 2756 , vOL. I IO] 
Weights are compared with standard copies at the observatory, and sets of certified weights are supplied to all who require them.

The Government analytical laboratory and assay office undertake a large amount of important work which falls under the headings of $(a)$ chemical and physical inspection of materials ; $(b)$ technical chemical consultations; and $(c)$ experimental research. Stores and materials of inferior quality frequently find their way on to the Egyptian market, and only by the systematic analysis of material tendered can these be eliminated and economies effected. To the same end the technical clauses in specifications governing supply by contractors are drafted by the staff of the laboratory.

The chemical work carried on in connexion with criminal investigation and other legal matters forms a branch of work which demands much time and great care. Recently published reports indicate that the consultative and research work is at present mainly related to questions affecting petroleum, and the development of petroleum resources in Egypt has given rise to an inquiry into the actual conditions under which petroleum products are used in Egypt, which was undertaken by the laboratory. The small refinery which the Egyptian Government has recently installed at Suez to deal, in the first instance, with royalty petroleum only, but with a view to its ultimate extension if that is found to be desirable, is also under the supervision of the director of the laboratory.

The first medical school in Egypt was formed in $\mathbf{r} 827$ at Abu Zabel by Clot Bey, a French doctor in the service of Mohammed Ali, and ten years later it was transferred to Qasr el Aini on the south side of Cairo, where it still remains. For many years the number of students was small, but of late the school has been much enlarged and the number now amounts to 387 . Attached to the school is the Qasr el Aini hospital, and these two form an important centre of scientific work in the country. There are now in the medical school well-staffed departments of biology, physics, chemistry, anatomy, physiology, pathology, and pharmacology, and in all of these not only is instruction given to students but research is carried on by the staff.

Although the number of scientific men in the institution has until recently been too restricted to admit of much research being undertaken in addition to teaching, several important investigations have been carried out; among these may be mentioned the study of the anatomy and racial characteristics of the ancient Egyptians, and of those neighbouring races whose remains occur in the cemeteries of the Nile Valley, and the comparison of them with the present inhabitants has added greatly to our knowledge of the Mediterranean peoples; the investigations which have been carried out of the life history of Ankylostoma and Schistosomum (Bilharzia) have done much to place our knowledge of these on a sound basis, the Bilharzia organism having been discovered in these laboratories, while work of no less importance has been done on the treatment of the diseases which are caused by these parasites. Valuable work on pellagra has also been done recently. Not only is there much mure to be investigated in the interest of Egypt itself, but the special conditions, climatic, racial, etc., which occur there provide opportunity for many promising lines of research.

The Department of Public Health, which dates from $\mathrm{I886}$, is also actively working in the same scientific field and, in addition to the administrative work which it carries on throughout the country, maintains several branches specialising in scientific work. Under the director of the laboratories of the department the water service carries out a regular inspection of all public water supplies, whether in the hands of the Government, municipalities, companies, or private individuals. The examination of substances having a direct bearing on questions of hygiene, such as foodstuffs, drugs, etc., is also undertaken in these laboratories, as well as the chemical and bacteriological examination of water.

Here too research on the main diseases of the country, ankylostoma, bilharzia, and typhus, is in progress with the co-operation of eminent specialists, and in this connexion the recent work of the late Mr. Bacot and of Dr. Arkwright will be recalled. An antirabic institute provides for the treatment of persons bitten by rabid animals. The annual reports of the Department indicate the wide scope of the scientific investigations which have to be undertaken in the course of its work, and highly expert assistance must without doubt be employed if they are to be brought to a successful conclusion under the peculiar conditions which an arid subtropical climate provides.

The special conditions which obtain in Egypt, a highly fertile soil, a controlled water supply rendering agriculture independent of rainfall, and a moderately hot climate, form the foundation of its agricultural wealth ; the prosperity of the country depends on the efficiency with which these favourable conditions are utilised, and to this end the irrigation engineer, the entomologist, the economic botanist, and the agricultural chemist are working in co-operation. Perennial irrigation has now been extended until about half the cultivable area is supplied with water at all seasons of the year, with the result that in normal years about 32 per cent. of that area is occupied by cotton. It will be evident therefore that the scientific institutions of the Ministry of Agriculture are of the highest national importance, and on their efficiency Egypt's prosperity must mainly depend.

In rgig a Cotton Research Board was appointed with the object of bringing together the heads of all the technical departments which were interested in the cotton crop, and to ensure that all problems relating to it were dealt with as adequately as possible. It was also to provide laboratory accommodation for investigators engaged in research on cotton. In its first annual report published last year the experimental work upon cotton which had been undertaken was reviewed, and a programme for further work at the scientific institutes of the Ministry was outlined. These institutes include laboratories, experimental farms, gardens, etc.

The chemical laboratory of the Ministry, which undertakes examination and study of soils, water manures, feeding stuffs, and agricultural products, is situated close to the botanical laboratory and the experimental farm. The work carried on at these has for its object the improvement of cotton, wheat, and

NO. 2756 , VOL. IIO 
other crops which are grown in the country, on the basis of field selection combined with self-fertilisation and hybridisation. One important and promising research which is in hand is the effect of the gradually diminishing "sharaki" (waterless) period on the soil flora. Propagation in bulk of improved strains of wheat and cotton is arranged with the State experimental farm and with selected private cultivators. The fungoid and bacterial diseases of Egyptian crops in general and of cotton in particular are investigated, and means for their control are devised and tested.

The supply of trustworthy cotton seed of the best growths is so important in order to produce a high quality of staple, and the opportunities of mixing good seed with inferior qualities before it reaches the cultivator are so many, that the Ministry actively interests itself in the matter, through the botanical laboratory.

To this may be added the important work which is being done on the flowering-curve method as an index to the effect of environmental conditions; or investigations of the causes of bud-shedding; and on the root systems of cotton plants. Similar attention is being paid to millet, rice, opium poppy, beans, and sesame; and sugar cane will be added shortly.

The Entomological Section undertakes the study and investigation of insect pests and advises on methods for their control. The fumigation of all cotton seed produced in the ginneries of Egypt is also controlled by this section, and samples of the seed obtained from ginning are sent to it for germination and examination for worms.

The work of the horticultural section should also be mentioned, for in it much work is being done in introducing and acclimatising new species or varieties of trees, and farm and garden plants.

Thus a beginning has been made to provide the scientific organisation necessary for the development of agriculture on sound lines, but something on a larger scale will be needed before it can be adequate to the country's requirements. In these institutions a number of questions of first-rate importance to the Egyptian cultivator are under study, such as the effect on the cotton crop of a high subsoil water-table, of rotation in irrigation, of reduced watering, and many others, and for their satisfactory solution the provision and efficient maintenance of a highly trained and experienced scientific staff is essential.
The scientific diagnosis and investigation of animal diseases are carried out at the veterinary pathological laboratory which was opened in $\times 904$, and the Serum Institute, which dates from 1903, provides the anticattle-plague serum required for the immunisation of cattle against cattle plague both in outbreaks and as a preventive measure.

Outside the State departments science is not widely represented in Egypt. There are a few scientific societies, of which the oldest is the Institut d'Égypte, which was founded in 1859 ; its object is the study of all that concerns Egypt and the surrounding countries from the literary, artistic, and scientific points of view. The Geographical Society was founded in 1875 and publishes bulletins and memoirs at intervals. In I92 5 the fiftieth anniversary of its foundation is to be the occasion of an international geographical conference.

The Cairo Scientific Society, founded in 1898 , is an active institution which meets fortnightly throughout the winter half of the year and publishes its proceedings monthly in the Cairo Scientific Journal. At Alexandria a hydrobiological institute has been recently established, and much important work awaits the scientific research which should be undertaken there. But these are all too few for the needs of the country, and their paucity suggests a lack of appreciation of the importance of scientific knowledge.

In spite of difficulties due to the war, which Egypt has experienced in common with most other countries, science has of recent years been playing a more and more important part in the development of the country and its resources. The conditions there prevailing often differ widely from those which have been studied in other countries, and much research by scientific men of high training and wide experience will be necessary before the many problems which present themselves are solved. Such work is not in the interest of Egypt alone, for much that is done there will, if it is of a high scientific standard, be a permanent addition to the general stock of knowledge. Egypt in the past has benefited largely by the science and technical skill which has been gradually built up by generations of students in many lands, and she may now furnish her own quota in return by scientific research in the many fields of inquiry which the Valley of the Nile affords.

\section{Gelatin.}

By Dr. T. Slater Price.

$\mathrm{G}^{\mathrm{E}}$ ELATIN, in the form of glue, has been so long known that, according to Dr. Bogue (J. Franklin Inst., I922, vol. 193, p. 795), "we are unable to penetrate the archives of the human race to a date where we may say with assurance that glue was not yet discovered. Certain it is that this material was in use as an adhesive in the days of the great Pharaohs of Egypt." As glue, or кó $\lambda \lambda \alpha$; it has given us the term "colloid," and at the time when this term was first used by Graham it was supposed that all colloids were substances of very complex constitution, such as is glue. This, however, is by no means the case, since what are known as the suspensoid colloids may consist of the elements them- selves, e.g. colloidal gold and silver. The emulsoid colloids, however, consist to a large extent of very complex chemical substances, as, for example, the proteins, and it is to this class that gelatin belongs. Because of its complex constitution the chemical investigation of gelatin and of the processes which occur in its extraction from bones and hides is still in its infancy, and essentially progress has only been made in the direction of the examination of the degradation products. It is therefore not to be wondered at that the enormous literature on gelatin consists, to a very great extent, of accounts of results obtained in the investigation of its colloidal properties. 